\title{
Stress Induced Cortisol Response in Young Women Classified as Restrained and Unrestrained Eaters
}

\author{
Laessle $\mathrm{R}^{*}$ and Lorig $\mathrm{F}$ \\ Department of Biological and Clinical Psychology, University of Trier, Trier, Germany \\ *Corresponding author: Laessle R, Department of Biological and Clinical Psychology, University of Trier, \\ 54286 Trier, Germany, Tel: +49 (0)651/201-2009, E-mail: laessle@uni-trier.de
}

Citation: Laessle R, Lorig F (2018) Stress Induced Cortisol Response in Young Women Classified as Restrained and Unrestrained Eaters. J Obes Overweig 4(1): 105. doi: 10.15744/2455-7633.4.105

Received Date: February 13, 2018 Accepted Date: May 26, 2018 Published Date: May 28, 2018

\begin{abstract}
Dietary restraint has been hypothesized to be a risk factor to develop disordered eating behavior with the consequence of clinical eating disorders such as bulimia nervosa or binge eating disorder. Because of mostly unsuccessful dieting efforts restrained eaters are supposed to suffer from stress, indicated by a higher cortisol response. The present investigation tested this hypothesis in 41 subjects undergoing a laboratory stress test with the measurement of salivary cortisol. The results show lower stress induced cortisol in the restrained eaters. This is discussed with regard to a possibly dysregulated intake behavior in restrained eaters.
\end{abstract}

Keywords: Stress; Cortisol; Restrained eating

\section{Introduction}

The eating disorders bulimia nervosa and binge eating disorder show prevalence rates up to $5 \%$ in community samples. Patients with bulimia nervosa usually are in the normal weight range. The core symptoms of the disorder are a bulimic attack that means the uncontrolled intake of a large amount of food (up to 10.000 calories) in a short period of time. Psychologically they are characterized by extreme concerns about weight and shape. Binge eating disorder (BED) is an eating disorder characterized by the recurrent uncontrolled intake of large amounts of food. In contrast to bulimia nervosa, BED subjects do not practice compensatory behaviors such as vomiting or the use of laxatives after a binge episode. Most of these individuals with BED therefore are obese. Due to their abnormal eating behavior both disorders show numerous biological aberrations in endocrine and neurotransmitter systems. For both disorders current etiological models are multifactorial, but postulate as a main vulnerability factor for the onset and maintenance repeated periods of dieting or the permanent practice of restrained eating. In particular, dieting has been linked to binge eating. This has been investigated in laboratory studies, which have shown that overeating under stressful conditions is a stable characteristic of restrained eaters. Dietary restraint describes the intention of individuals to restrict their food intake in order to achieve weight loss or to prevent weight gain. Restrained eaters cognitively instead of physiologically control their eating behavior under normal circumstances. The behavioral strategies involve for example deliberately limiting one's food intake per day, calculating consumed energy, avoiding high calorie dishes, ending a meal before reaching satiety, and frequent weighing. Data on cortisol levels in restrained eaters are sparse. An early study of [1] collected blood samples overnight for measuring cortisol in restrained and unrestrained eaters. The cortisol levels were not significantly different between the two groups, but this might be due to the very small sample size of only 22 subjects. A more recent publication of [2] found elevated levels of unstimulated salivary cortisol in restrained eaters. The results were interpreted as an indicator of stress because of largely unsuccessful dieting efforts.

Whether acute stress provokes changes in cortisol in restrained eaters is still unclear and was therefore tested in the present study.

\section{Method}

41 healthy women aged 18-30 years were recruited through advertisement in local newspapers. Exclusion criteria included oral contraceptive use, smoking, and regular alcohol consumption to assess the presence of any of these exclusion criteria, participants were examined and interviewed by a physician. All women were paid for participation. Classification in restrained and unrestrained eaters for the present study was done according to norm tables from [3]. 17 had a low restraint score, 24 were high in dietary restraint. Participants were exposed to the Trier Social Stress Test, a standardized laboratory stressor. The TSST consisted of a 
three-minute speech preparation period, a five-minute public speaking task in front of two evaluative, non-responsive audience members and a five-minute challenging serial subtraction task. The TSST is a validated tool to provoke psychobiological stress responses. Salivary cortisol samples were available at $+30 \mathrm{~min}$ and at $+60 \mathrm{~min}$ after stress.

Saliva samples were collected using salivettes (Sarstedt, Nümbrecht, Germany), plastic vials with cotton dental rolls inside, and frozen at $-20^{\circ} \mathrm{C}$ until laboratory analysis.

\section{Results}

Table 1 shows salivary cortisol after stress for the restrained and unrestrained women.

\begin{tabular}{|c|c|c|}
\hline Measurement points & unrestrained & restrained \\
\hline$+30 \mathrm{~min}$ & $9.1 \pm 5.3 \mathrm{nmol} / 1$ & $6.6 \pm 3.2 \mathrm{nmol} / 1$ \\
\hline$+60 \mathrm{~min}$ & $6.2 \pm 3.3 \mathrm{nmol} / 1$ & $4.4 \pm 1.9 \mathrm{nmol} / \mathrm{l}$ \\
\hline
\end{tabular}

Table 1: Salivary cortisol after stress for the restrained and unrestrained women

The means between the comparison groups at each measurement point after stress were compared by t-Test with two tailed significance level. $30 \mathrm{~min}$ after stress as well as $60 \mathrm{~min}$ after stress restrained eaters had lower mean cortisol levels. $\mathrm{T}(39)=1,8, \mathrm{p}$ $=.07 ; \mathrm{T}(39)=2,1, \mathrm{p}=.04$.

\section{Discussion}

Restrained eaters in our study showed lower mean cortisol after an acute stressor. This is not in line with former studies [1,2] finding no differences or higher levels, therefore hypothesizing that restrained eaters suffer from stress because of unsuccessful dieting efforts. The results are also somewhat contradictory to the study of McLean et al. [4] for urinary cortisol. But these data are not directly comparable, because stress was not recorded. The same is true for the study of Rideout et al. [5]. Support for the presented data comes from Durguerian et al. in weight lifters [6], who showed lower cortisol after dieting. Our results of lower stress induced cortisol may be explained partly by a habitually successful cognitive control of eating in the restrained eaters. This was not fulfilled in the study of Tomiyama et al. [7]. Their participants underwent a strict diet, were markedly stressed and therefore showed significantly elevated cortisol. A further explanation is the effect of glucocorticoids on food intake [8]. Tendentially lower stress induced cortisol in restrained eaters may be a hint for a dysregulation of HPA axis, which in turn may promote eating disorders [9].

There are limitations of this study that indicate to interpret the present results with care. The sample size was relatively small and only women in a specific age range were tested. A laboratory setting was used and a transfer to the natural environment of the participants is not possible. Although significant influences of the stage of the menstrual cycle on cortisol secretion have been reported by [10], we cannot exclude confounding effects for our results.

\section{Conclusion}

Although confounding influences of stage of the menstrual cycle could not be ruled out, the lower stress induced cortisol secretion which was observed in restrained eaters may make them vulnerable for a dysregulation of intake behavior which in turn promotes eating disorders such as binge eating and obesity.

The present data were collected as part of the master thesis of the second author (F. Lorig).

\section{Compliance with Ethical Standards}

Informed consent was obtained from all individual participants included in the study.

\section{References}

1. Pirke KM, Tuschl RJ, Spyra B, Laessle RG, Schweiger U, et al. (1990) Endocrine findings in restrained eaters. Physiol Behav 47: 903-6.

2. Anderson DA, Shapiro JR, Lundgren JD, Spataro LE, Frye CA (2002) Self-reported dietary restraint is associated with elevated levels of salivary cortisol. Appetite 38: $13-7$.

3. Pudel V, Westenhöfer J (1989) The questionnaire on eating behavior (FEV) [Der Fragebogen zum Eßverhalten (FEV)], Hogrefe, Göttingen, Germany.

4. McLean JA, Barr SI, Prior JC (2001) Cognitive dietary restraint is associated with higher urinary cortisol excretion in healthy premenopausal women. Am J Clin Nutr 73: 7-12.

5. Rideout CA, Linden W, Barr SI (2006) High cognitive dietary restraint is associated with increased cortisol excretion in postmenopausal women. J Gerontol A Biol Sci Med Sci 61: 628-33.

6. Durguerian A, Filaire E, Drogou C, Bougard C, Chennaoui M (2018) Food restriction alters salivary cortisol and a-amylase responses to a simulated weightlifting competition without significant performance modification. J Sports Sci 36: 536-44.

7. Tomiyama AJ, Mann T, Vinas D, Hunger JM, Dejager J, et al. (2010) Low calorie dieting increases cortisol. Psychosom Med 72: $357-66$.

8. Dallman MF, la Fleur SE, Pecoraro NC, Gomez F, Houshyar H, et al. (2004) Minireview: glucocorticoids--food intake, abdominal obesity, and wealthy nations in 2004. Endocrinology 145: 2633-8. 
9. Crowther JH, Hobfoll SE, Stephens MA, Tennenbaum DL (1992) Chronic dieting and eating disorders: A spiral model. In: The etiology of bulimia nervosa: The individual and familial context. Washington DC: Hemisphere, USA

10. Wolfram M, Bellingrath S, Kudielka BM (2011) The cortisol awakening response (CAR) across the female menstrual cycle. Psychoneuroendocrinology: 36: 905-12.in 2004. Endocrinology 145: 2633-8.

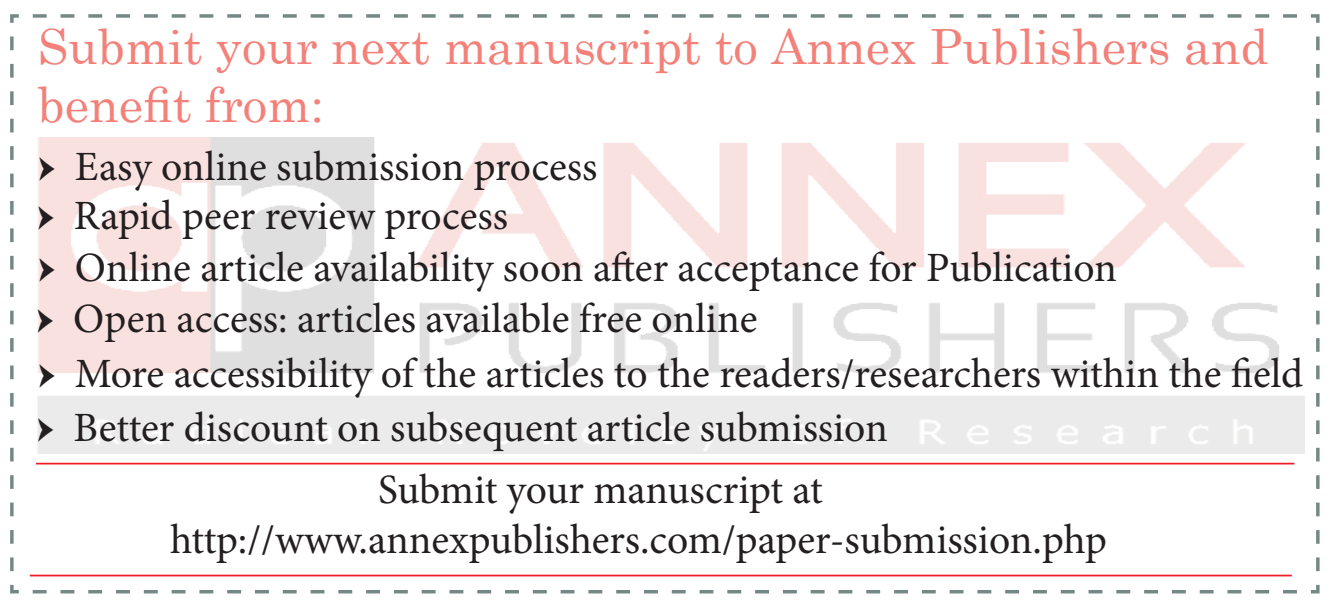

